\title{
ISRUP E-Service Framework Balanced Scorecard to Measure the Capabilities from the Methodologies, Processes, Notations, Life Cycles, and Standards
}

\author{
Seyyed Mohsen Hashemi ${ }^{1}$, Mohamadreza Razzazi ${ }^{2}$, and Mohamad \\ Teshnehlab ${ }^{3}$ \\ 1 Computer Engineering Department, Islamic Azad University, Science \\ and Research Branch smohsen_hashemi@yahoo.com, Tehran, Iran \\ www.isrup.com \\ 2 Computer Engineering Department, AmirKabir University of \\ Technology razzazi@ce.aut.ac.ir \\ 3 Electronic Engineering Department, KNT University, Tehran, Iran
}

\begin{abstract}
Despite the fact that nowadays, architectures, development processes, frameworks and technologies are maturing to be Service Oriented Architecture (SOA). Former frameworks for enterprise architecting couldn't be matched with those SOAs. Thus putting to use those frameworks to the business enterprises make IT/ICT consultants and enterprise architects encounter with some complex difficulties in the enterprise architecting projects. ISRUP E-Service Framework is proposed and developed based on SOA and RUP to converge E-Business, ECommerce and E-Government concepts through just leveraging E-Services (especially web and grid services) by architecting the information systems in the enterprises. This paper explains the results of the benchmarks which done in between ISRUP E-Service Framework and 21 different methodologies, processes, notations, life cycles and standards pertaining to their capabilities.
\end{abstract}

\section{Introduction}

The Rational Unified Process is a software engineering process developed and marketed originally by Rational Software, and now IBM. It is a disciplined approach to assigning and managing tasks and responsibilities in a development

Please use the following format when citing this chapter:

Mohsen Hashemi, S., Razzazi, M., Teshnchlab, M., 2006, in International

Federation for Information Processing, Volume 205, Research and Practical Issues of Enterprise Information Systems, cds. Tjoa, A.M., Xu, L., Chaudhry, S., (Boston:Springer), pp.255-259. 
organization. The goal of this process is to produce, within a predictable schedule and budget, high-quality software that meets the needs of its end users [1].

ISRUP is an E-Service framework for Agile Enterprise Architecting through Unified Modeling Language (UML) and RUP terminology to improve the enterprise architecture of business enterprises, ISRUP E-Service Framework has 40 enterprise patterns to apply an iterative process for continuous improvement by way of information system architecting. ISRUP E-Service framework depicted that the convergence of E-Business, E-Commerce and E-Government through just E-Services. Each enterprise that wants to be as a service requester, service provider and service broker, should apply ISRUP enterprise patterns to be prosperous. ISRUP stands on Integrated Services-Information Systems based on Rational Unified Process terminology. ISRUP E-Service framework is used by some parts of government and businesses to make informative and reusable documents as their assets. For more information please see www.isrup.com [2]. After ISRUP E-Service framework Odyssey, 5 views and 8 models of ISRUP EService framework are explored in the following. What comes as final is ISRUP E-Service Framework Balanced Scorecard that shows the results from benchmarking different methodologies, processes, notations, life cycles and standards.

\section{ISRUP E-Service Framework Odyssey}

ISRUP E-Service framework is derived from Zachman enterprise architecture framework and IBM Rational software development process. The framework mainly uses RUP and UML terminologies respecting to the enterprise architecture documentation. The framework doesn't claim to use the same terms and expressions as Zachman framework and RUP process, but according to the facts in the enterprises (especially Government and Businesses); it has tried to develop framework components with respect to the future technologies (SOA) and the past useful experiences. ISRUP E-Service Framework consists of 5 views (Stakeholder, Analyst, Architect, Designer and Developer) and 8 models (Proof, Process, Place, People, Period, Purpose, Practice, and Project (8P)) $[3,4,5$, and $6]$.

\section{ISRUP E-Service Framework Views}

The 40 enterprise patterns fit into 5 views that don't necessarily adapt with the views of other frameworks syntactically, semantically and pragmatically. These views are described as follows $[7,8]$. 
Stakeholder View, This view addresses the activities and artifacts of the enterprise patterns from the view of stakeholders. All models are simplified and understandable for them.

Analyst View, The emphasis of the view is on requirements \& requirements analysis. Analysts analyze the requirements from different aspects. The view is a conceptual view to the enterprise-wide requirements.

Architect View, Focuses on integration and homogeneity of the components in the models, in addition to this view is platform-independent.

Designer View, All the models in this view emphasize on clearance and determining the design details and generally all of the details. These details are dependent on the technology and thus they are platform-dependent.

Developer View, This view addresses implementation and test details and generally details of controlling any development in enterprise's projects and activities, especially for software development activities.

\section{ISRUP E-Service Framework Models}

Proof, Process, Place, People, Period and Purpose models are considered extensions of what, how, where, who, when and why in the Zachman framework, consecutively. Practice and Project models are added to the Zachman to support and leverage the experiences and resolving the problems and changes in terms of projects. ISRUP models (8P) are described in the following [3-6, and 8].

Proof Model, 5 enterprise patterns pertaining to this model emphasize on entities, persistent object, data tables and generally any kind of repository, which can be created in an enterprise.

Process Model, The enterprise patterns relating to this model emphasize on how the enterprise processes collaborate to use the enterprise resources, and especially on their interaction with elements of the proof model.

Place Model, The enterprise patterns of this model emphasize on logical and physical positions for network elements. For example buildings, rooms, floors, etc. are physical and IP is a logical position. This model addresses the way to order and organize all of the software and hardware components to take more secure advantages of information technology.

People Model, This model emphasizes on human resources and their relationship with information resources (knowledge) of an enterprise, for example; the owner of information systems and access levels are determined in this model.

Period Model, This model emphasizes on all reactions the enterprise must have toward immediately to manage internal and external events.

Purpose Model, This model emphasizes on all of the matters related to ROI, vision and generally all of the subjects relating to the enterprise goals. 
Practice Model, This model emphasizes on taking advantage from success and failure experiences from people and other organizations to resolve the common problems from all viewpoints.

Project Model, This model includes the stages of understanding the problem statement, determining the projects to resolve the problems and taking advantage from external resources to simplify and speed solving problems. Subcontracting and controlling what would be outsourced are herein.

\section{ISRUP E-Service Framework Balanced Scorecard}

Different methodologies, processes, notations, life cycles and standards such as ITU-T SG $* / 4$, Web Services, SOA, OMG-MDA, P of EAA, UML 2.0, UN/CEFACT-UMM, IBM RUP®, Goal UML, EUP, Zachman, GEM- MDEM, EAP, TOGAF, DoDAF-C4ISR, FEAF, TEAF, Balanced Scorecard, $\mathrm{CMM} / \mathrm{CMMI} / \mathrm{ISO}$, Six Sigma, and Porter share common issues that in order to use them simultaneously (they are called Enterprise Patterns in ISRUP E-Service Framework). The important point is that, we'll need to integrate all of them in a holistic framework.

All above methodologies, processes, notations, life cycles and standards have been compared with together through 40 enterprise patterns of ISRUP E-Service Framework in Table 1. ISRUP E-Service Framework Balanced Scorecard (BSC) as a measurement instrument has been used to specify the importance level of all methodologies, processes, notations, life cycles and standards which they have claim on their enterprise-wide solutions, partially or completely. So the value of each cell encompasses the elements of knowledge and documentation. For each of these methodologies, processes, notations, life cycles and standards, the result of each enterprise pattern of ISRUP E-Service Framework can be assessed from 3 different situations.

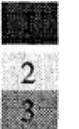

Status $1=$ uncertain or not documented

Status $2=$ partly known and partly documented

3. Status $3=$ fully known and well documented certainly

Table 1 shows relatively the significant scores of those methodologies, processes, notations, life cycles and standards rather than ISRUPE-Service Framework score (120) in different presentations as Table 1. This benchmark shows that IBM RUP $\otimes$, ITU-T SG */4, and OMG MDA have got 100, 82, and 74 marks, subsequently. 
Table 1. Results of Benchmarking Methodologies, Processes, Notations, Life cycles and Standards based on ISRUPE-Service Framework patterns (ISRUP score $=120$ )

\begin{tabular}{|c|c|c|c|c|c|}
\hline $\begin{array}{l}\text { Methodglogies, } \\
\text { Processes, Notations } \\
\text { Life cycles and Standards }\end{array}$ & $\begin{array}{l}\text { BSC } \\
\text { Score }\end{array}$ & $\begin{array}{l}\text { Methodologies, } \\
\text { Processos, Notations, } \\
\text { Life cycles and } \\
\text { Standards }\end{array}$ & $\begin{array}{l}\text { BSC } \\
\text { Score }\end{array}$ & $\begin{array}{l}\text { Methodologies, } \\
\text { Processes, Notations, } \\
\text { Lific cyelos and } \\
\text { Standards }\end{array}$ & $\begin{array}{l}\text { BSC } \\
\text { Score }\end{array}$ \\
\hline IBM RUPQ & 100 & Zachman & 68 & CMM CMMI ISO & 69 \\
\hline ITU-T SG*/4 & 82 & GEM MDEM & 70 & Six Sigma & 62 \\
\hline Web Services & 62 & EAP & 56 & Porter & 57 \\
\hline SOA & 57 & TOGAF & 57 & Goal UML & 72 \\
\hline $\mathrm{OMG} \mathrm{MDA}$ & 74 & DoDAF C4ISR & 67 & EUP & 69 \\
\hline P of EAA & 64 & FEAF & 57 & Balanced Scorecard & 53 \\
\hline UML 2.0 & 51 & TEAF & 58 & UN/ CEFACT UMM & 68 \\
\hline
\end{tabular}

\section{References}

1. P. Kruchten, Rational Unified Process - An Introduction, 3rd edition (Addison-Wesley). 2. S.M. Hashemi, Business Process Improvement through ISRUP, Requirement Driven approach with UML (ISBN: 964-7073-56-9).

3. CIO Council, A Practical Guide to Federal Enterprise Architecture. A U.S. Government publication prepared by the U.S. Government CIO Council and released in September 1999.

4. S.H. Spewak, Enterprise Architecture Planning: Developing a Blueprint for Data, Applications, and Technology (John Wiley \& Sons, September 1993).

5. C. O'Rourke and N. Fishman, Enterprise Architecture Using the Zachman Framework (Course Technology, March 24, 2003).

6. J.A. Zachman, A Framework for Information Systems Architecture, IBM Systems Journal 26(3), 276-292 (1987).

7. S.M. Hashemi, ISRUPE-Service Framework for Agile Enterprise Architecting (Manuscript, 2006).

8. M. Razzazi and S.M. Hashemi, Requirement Modeling Pattern as a New Process Pattern, The 6th World Multiconference on Systems, Cybernetics, and Informatics, Orlando, USA, 2002 